\title{
Zero-grazing smallholder dairy cow systems in semi-arid areas of central Tanzania: the HADO programme
}

\author{
R. B. Ogle ${ }^{1}$, C. M. Shayo ${ }^{2}$ and H. Wiktorsson ${ }^{1}$ \\ 'Department of Animal Nutrition and Management, Swedish University of Agricultural Sciences, \\ Box 7024, 75007 Uppsala, Sweden \\ ${ }^{2}$ Livestock Production Research Institute, Box 202, Mpwapwa, Tanzania
}

\section{Introduction}

The HADO (Soil Conservation in Dodoma Region) programme was started in 1973 and was initially concerned with arresting land degradation in Dodoma region in central Tanzania through physical control measures. However, in spite of the efforts made, rates of erosion were clearly accelerating in many areas, mainly as a result of severe overgrazing. Therefore, in 1979 and 1986, decisions were taken to evict forcibly all grazing livestock from two of the worst affected areas, of 1200 and $700 \mathrm{~km}^{2}$, respectively. This caused considerable hardship for the agropastoral societies in and around these areas and it was decided recently to allow the reintroduction of a limited number of zero-grazed, improved dairy cows, provided certain preconditions were met: (i) only crossbred or Mpwapwa (a local dual-purpose breed) cattle would be allowed, with a maximum of three cows and one bull per smallholding, housed in a suitable cowshed and restricted to a radius of $50 \mathrm{~m}$ from the homestead; (ii) a minimum of 0.5 ha of improved grass or grass/legume pasture should be established; (iii) a permanent water source should be available within reasonable distance of the homestead; (iv) veterinary drugs, etc., including hand sprays against ticks should be available locally.

A SAREC (Swedish Agency for Research Cooperation with Developing Countries) supported research project was started in 1989 with the aim of assisting farmers in developing appropriate feeding and management systems, and monitoring the results.

\section{Methods}

The feeding systems are based on crops and crop residues, legume trees, agroindustrial by-products, cut and conserved forages, improved grass/legume pastures. The project is interesting in that zero- grazing systems are unusual in semi-arid areas and farmers in central Tanzania have no previous experience of such systems. A series of feeding trials and metabolic experiments are in progress at the Mpwapwa Livestock Production Research Institute in order to evaluate foodstuffs and feeding strategies under controlled conditions.

\section{Results and experiences from the first year of the project}

Over 20 smallholders have met the requirements for keeping cattle and have been supplied with improved heifers, mainly Friesian crosses. However, over 10 times this number have expressed strong interest in joining the project, but have been prevented from doing so due to an acute shortage of grade heifers in Tanzania, which is the main constraint to expansion of the programme. It was decided therefore to allow farmers to bring in selected local zebu cows for upgrading with Mpwapwa or crossbred bulls. Milk yields currently range from 5 to $19 \mathrm{~kg} /$ day, with an average of $9.5 \mathrm{~kg}$. Local fresh milk prices are equivalent to around US\$ 0.60 per litre, and as by-product concentrates such as maize bran and sunflower seed cake cost less than US\$ 0.05 per $\mathrm{kg}$, profitability is very satisfactory. Stands of napier grass (Pennisetum purpurcum), Leucaena spp. and sugar cane have been established on contour ridges to provide both fodder and erosion control, although attempts by farmers to establish mixed pastures of buffel grass (Cenchrus ciliaris), rhodes grass (Chloris gayana) and Macrotyloma spp. for hay making have been largely unsuccessful. Crop residues, such as maize and sorghum stover, sweet potato vines, groundnut haulms and banana stems, etc., are important dry season foods, together with leaves and pods from local legume trees such as Acacia albida. The problem of water supply has been solved on some smallholdings by feeding large 
quantities of water melons, intercropped with maize. On-station feeding trials and metabolic experiments are in progress to establish the nutrient value of acacia pods and water melon seeds, pulp and rind.
Acknowledgement

The authors wish to acknowledge support from the Swedish Agency for Research and Cooperation with Developing Countries (SAREC). 